\title{
Knowledge Management in collaborative engineering
}

Waguih EIMaraghy

\author{
Faculty of Engineering, \\ Department of Industrial and Manufacturing \\ Systems Engineering (IMSE), \\ Intelligent Manufacturing Systems Centre (IMS), \\ University of Windsor, Windsor, Ontario, N9B 3P4, Canada \\ E-mail: wem@uwindsor.ca
}

\begin{abstract}
Collaboration has always been a key driving force behind human civilisation, and an integral part of the engineering profession. Engineered systems such as manufacturing systems and information systems are generally complex. Knowledge is inextricably bound up with human cognition, and the management of knowledge occurs within a complex environment. It is also essential for those designing KM systems to consider the human and social factors at play in the production and use of knowledge. This paper presents a systems analysis and design approach to support the design information and the methodologies needed for both a comprehensive and consistent design process.
\end{abstract}

Keywords: information technology; KM; knowledge management; collaborative engineering; engineering design; system analysis and design.

Reference to this paper should be made as follows: ElMaraghy, W. (2009) 'Knowledge Management in collaborative engineering', Int. J. Collaborative Engineering, Vol. 1, Nos. 1/2, pp.114-124.

Biographical notes: Waguih ElMaraghy, $\mathrm{PhD}$, PEng is Professor and Head of the Department of Industrial and Manufacturing Systems Engineering (IMSE), University of Windsor, and Director of the Intelligent Manufacturing Systems Centre (IMS). He is a former Chief Design Engineer at DOFASCO and was also a tenured full Professor at the University of Western Ontario and the founding Director of the Design Automation Lab., Department of Mechanical Engineering, Faculty of Engineering Science. He is a fellow of: the International Production Engineering Academy (CIRP), the American Society of Mechanical Engineers (ASME), and of the Canadian Society for Mechanical Engineering (CSME).

\section{Introduction}

Globalisation has revolutionised business, and is forcing changes to everything from innovation, to Product Development (PD) and manufacturing, and is similarly forcing collaborative and distributed activities and networking. The recent Internet revolution has enabled engineers to engage in virtual teaming remotely across geographical, temporal, and disciplinary boundaries, making collaborative engineering easier. 
To date, researchers from various disciplines have employed different theories and techniques to study the general subject of collaboration. For example, the optimisation research community models a collaborative engineering activity as a multi-objective optimisation problem, wherein weighting factors are assigned, a priori, to stakeholder concerns. Scholars from business research communities have considered collaborative engineering activities from the project management perspective, suggesting various teaming strategies to improve organisational effectiveness. Collaborative engineering activity has also been an active subject of research in the information science community, especially in the areas of database and computer-supported collaborative work.

Knowledge Management (KM) is often seen as a problem of capturing, organising, and retrieving information, evoking notions of data mining, text clustering, databases, and documents. This view is too simplistic. Knowledge is inextricably bound up with human cognition, and the management of knowledge occurs within a complex environment, including the social context, as illustrated in Figure 1. It is therefore essential for those designing KM systems to consider the human and social factors at play in the production and use of knowledge.

Figure 1 Knowledge Management architecture summary (see online version for colours)

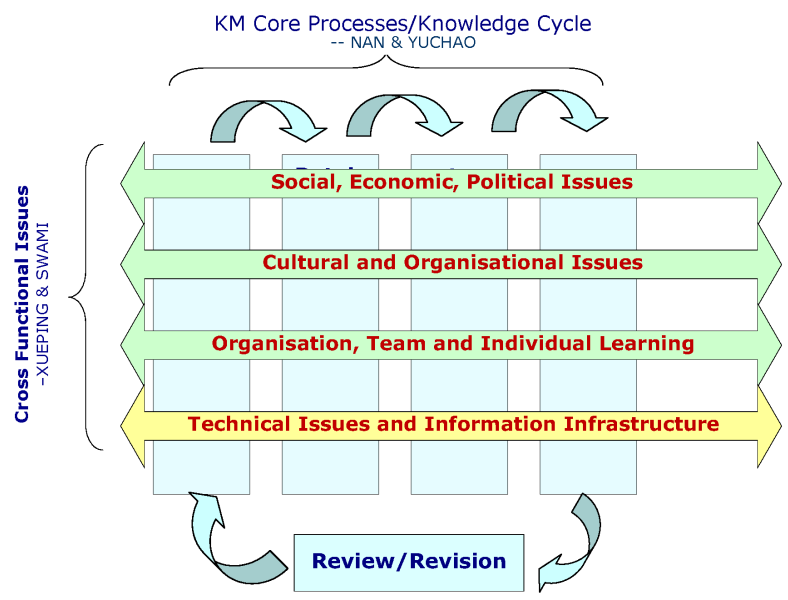

Source: Bhatt (2000)

Engineered systems such as manufacturing systems, information systems, transportation and communication systems, logistics and organisational systems; can be very complex and complicated. New theories, such as the sciences of complexity and design theories and methodologies, and socio-technical theories are examined for their relevance to innovation and policy-making for economic growth and development. In designing products and systems, the goal is often to reduce complexity so as to ensure that the system is robust, and guarantee its long-term stability, while minimising the cost.

This paper presents a systems analysis and design approach to support the design information and the methodologies needed for both a comprehensive and consistent design process. The paper discusses and illustrates the application of system analysis and design methods for the definitions and analysis of the design problem objectives, the functional requirements and architecture, conceptual design as well as physical modelling. 


\section{Product realisation methodologies}

\subsection{Design theories and methodologies}

Design representation technology such as: geometry, solid modelling, tolerancing, and computer graphics; and design analysis tools including: numerical methods, computer simulation, and finite-element modelling have evolved significantly over the past decades. The classical machine design authors such as Spotts, Shigley, and Dieter gave us comprehensive and well organised knowledge on which to build, particularly in detail design, to satisfy the design requirements for strength, power, and production. Their approach can also be called the 'components', or 'bottom-up', approach which is founded on the belief that any mechanical system can be broken into independent components and these can be optimised to form the design. Pahl and Beitz (1976) opened the door to a 'structured' approach to design that relates function and physical effects. The research in engineering design optimisation, although applied to components design, it is a general enough methodology and therefore has found applications in structural analysis, shape optimisation, configuration, systems design as well as in the optimisation of composite material properties. Group technology, computer aided design, Computer Aided Engineering (CAE), Computer Aided Manufacturing (CAM), and Product Data Management (PDM) have supported the design of mechanical components. Feature-based design allowed the simultaneous design and process planning of components (ElMaraghy, 2001). This model in its simplest form is illustrated by the Triad Model for Engineering Design, in Figure 2.

Figure 2 A triad model for engineering design (see online version for colours)

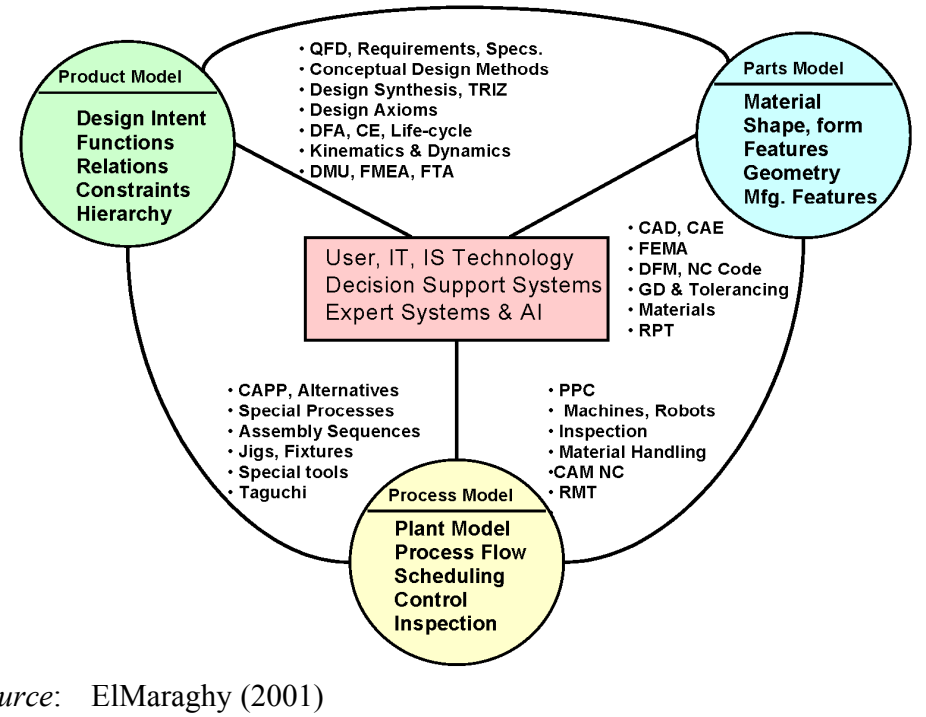

\subsection{Collaborative product development}

Increased global competition requires the ever increased speed in product realisation with the highest quality and least cost. This is simultaneously happening with an increased complexity, variety and/or sophistication of most products. The automobile for instance 
is growing in functionality and in integration of many components from mechanical to electronics to sensors and on-board computers, navigation, control and audio-systems. Furthermore, the system solution, to achieve the broad quality targets, does not only consider the initial product design and production, but also includes life-cycle and environmental issues. The PD and realisation has therefore evolved from an era of machine technology, then information technology in the 1990s, where knowledge Engineering is prominent to the 21st trend of Collaborative Engineering and Team Work, and whole life-cycle issues, as illustrated in Figure 3.

Figure 3 Product realisation trends (see online version for colours)



\section{Knowledge definition and acquisition}

\subsection{Data, information and knowledge}

Knowledge is information combined with experience, context, interpretation, and reflection. It is a high-value form of information that is ready to apply to decisions and actions. Explicit or codified knowledge refers to knowledge that is transmittable in formal, systematic language. On the other hand, tacit knowledge has a personal quality, which makes it hard to formalise and communicate. Figure 4 explains the relationship between data, information and knowledge. KM seeks to understand the way in which knowledge is used and traded within organisations and treats knowledge as self-referential and recursive. KM treats knowledge as a form of information which is impregnated with context based on experience. 
Figure 4 Data, information and knowledge (see online version for colours)

\section{What is Knowledge?}

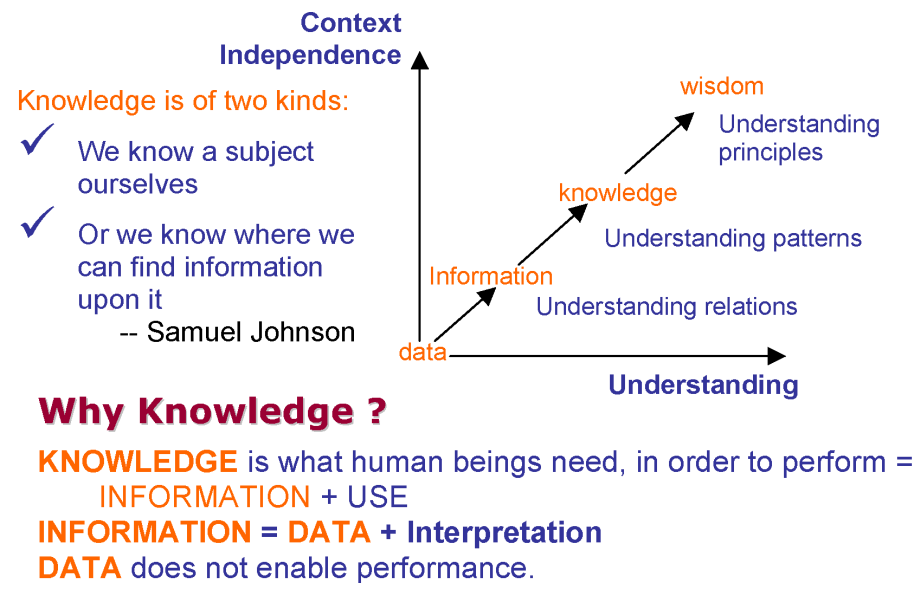

\subsection{Knowledge acquisition}

Ever since the development of Artificial Intelligence (AI) and expert systems, there has been the promise of capturing an organisation's knowledge at a large scale and making it available to the entire organisation. While there have been several early success stories, attempts to acquire the broad knowledge of organisations have been less fruitful (Buchanan and Smith, 1988). More than a decade later, an optimistic survey by Wagner (2004) finds that no more than a third of the organisational knowledge is available in computerised form, and that much of today's organisational knowledge still exists outside of formal information repositories and often only in people's heads. While organisations are eager to capture this knowledge, existing acquisition methods are not up to the task. Neither traditional AI-based approaches nor more recent, less-structured KM techniques have overcome the knowledge acquisition challenges. Obviously, knowledge acquisition is a challenge. We need to be concerned with the acquisition as well as the maintenance of the organisational knowledge. How can we extract more of the existing knowledge from organisational sources, especially from people? And how can we manage the maintenance so as to assure that the stored knowledge is accurate and up-to-date?

\subsection{Collaborative engineering for product life cycle management}

The three dimensional solid model of a product is the connecting link between the

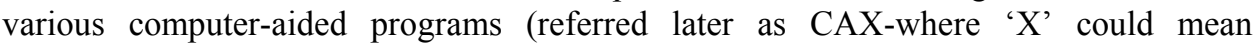
design, engineering, manufacturing, planning or inspection). The programs generate a huge amount of data, which includes the solid models of different iterations and previous versions of products, as well as tooling, materials, process plans, and results of analysis. This necessitates a systematic approach to data storage, verification, and retrieval-achieved by a PDM system. The PDM systems have rapidly evolved over the last decade, and now allow distributed storage and remote access over internet. They provide better data translation for exchange among various teams. 
A complete set of computer-aided programs, PDM system, and collaboration utilities, is now referred to as a-Product Lifecycle Management (PLM) solution.

A well-designed product will satisfy all the functional requirements, including the ease of manufacture, maintenance, delivery, and disposal. Design for Manufacture (DFM) is influenced by product geometry, material, and process. For example, injection moulded plastic parts need to be designed with a uniform wall thickness to minimise the production cycle time, and avoid sink marks; metal castings must be designed for directional solidification for ease of feeding; etc.

Similar guidelines are also available for improving a product design for ease of assembly, service, transportation and environment. Design for Assembly (DFA) guidelines include: reduction of number of parts, and number of assembly directions. Design for Service guidelines include modular design, and ease of access. Design for Handling and Logistics guidelines include provision of suitable hooks and handles for lifting the part. Design for Environment (DFE) guidelines include use of recyclable materials (metals are better than plastics), reduced packaging, and improving the energy efficiency of the product. The guidelines (referred later as DFX - where X could mean manufacture, assembly, service, transportation, or environment) are distilled from practical experience on previous products, and may not be applicable to new materials or processes. They may also conflict with each other, but provide no quantitative feedback to resolve such conflicts.

The collaborative engineering framework also yields an important by-product: a vast amount of data and information captured in digital form during development of several generations of products. KM is in fact, rapidly becoming an important part of PLM.

The focus of PLM on engineering data and knowledge, contrasts with enterprise resource planning, supply chain management and customer relationship management, which largely handle business process data. There is however, an increasing overlap between the systems and the distinctions are gradually blurring. In future, it is likely that the systems will have seamless connections and data exchanges with each other, and will provide access to any relevant data through a standard user interface.

\subsection{Design theories and methodologies}

Geoff Boothroyd's work pioneered DFA and opened the door for all 'Design For X'. Dixon and Poli have also contributed significantly, through their research and publications, to the design for manufacturability area. Their text also includes a structured approach to design (Dixon and Poli, 1995) which is influenced by the earlier engineering design and DFM contributors.

These methods are part of what is known as concurrent or simultaneous engineering. With Design for Manufacturing and Assembly (DFMA), component design started to take into consideration the life cycle process requirements. Both the DFA and the Axiomatic design methodologies represent 'top-down' approaches that can be applied at the various stages of the design, starting with the conceptual design of the product. Suh's (1988) research created an axiomatic approach to design for both form and design of new materials. 
Engineering design synthesis continues to stand as an ill-understood and complex human creativity activity. The utilisation of information-based system analysis and design tools would enhance the process of analysing the functional requirements, starting with the customer, until the delivery of successful products introduction (ElMaraghy, 2001).

From the above discussion, it appears that the approach to engineering design innovation has, over the years evolved, in at least four waves:

- Components and Sub-assemblies (Bottom-Up Approach, Modularisation)

- Product/Parts/Process (Concurrent Engineering (CE), Triad Model)

- Design Theory and Methodology (Axioms, scientific, IT, KE, Hierarchical Architecture)

- Systems Engineering (Interdisciplinary, Holistic Pyramid Structure, Multiple Integrated Views).

\section{Systems approach for design modelling}

\subsection{Modelling and managing complexity}

Modelling is one of the fundamental activities in engineering; it is required to present knowledge and explore solutions to a whole range of problems. The consequence of meeting customer requirements and maintaining a high level of multi-disciplinary technologies in products raises the issue of complexity. Management of complexity does start with the early phases of the product realisation process. ElMaraghy and Urbanic (2003) developed a novel method for modelling manufacturing systems complexity. Some authors have concluded that through design modularisation, and product/process integration, success in product realisation is achieved (Marshall et al., 1998). This is true to a great extent, provided modularity is not seen purely as a process of decomposition of product architecture into sub-assemblies, and subassemblies into components. It must also be emphasised that for a comprehensive and correct solution, the entire system design must closely meet all the functional requirements.

\subsection{Modularisation, product/process integration}

Design modularisation is an integrated structured approach to meeting the demands of the rapid realisation of products (Marshall et al., 1998). The efficacy of the approach is demonstrated through a case study of modularity applied to a 'measurement whilst drilling' electronic sensor for civil engineering and oil applications. The paper presents a mixed technology platform comprising mechanical, electronic and software elements, not unlike many new industrial and consumer products. Modules, as opposed to subassemblies, have a number of characteristics and fundamental differences between them: 
- modules are cooperative subsystems that form a product, a manufacturing system, a business or an enterprise, etc.

- modules have their main functional interactions within, rather than between, modules

- modules have one or more well defined functions that can be tested separately and are a composite of the components of the modules

- modules are independent and self contained and may be combined and configured with similar units to achieve a different overall function.

Modularity, as a key aspect of a mass customisation approach, may be used to meet customer requirements and move from economies of scale to possibilities within economies of scope; a key for dealing with this complexity. However, a systems engineering framework is required.

Loureiro and Leany (1999) have proposed a systems engineering framework for integrated automotive development. Their modelling framework is intended to integrate the product, its life cycle processes and their associated organisations throughout the requirements, functional and physical analysis processes, at all levels of the product breakdown structure, deriving attributes as emergent properties of a whole integrated system. The paper justifies the framework through a review of traditional and current automotive development and two case studies. It is justifiably argued that CE, represented at best by the triad product/parts/process design in Figure 2, does not provide the complete framework to deal with the complexity of such multi-domain complex systems. It is stated that the level of integration and complexity of automobile functionality requires a better understanding of the contribution of each product and/or process component to the whole and the interactions between these components. CE of components helps component evolution, but only an interdisciplinary, collaborative approach to derive, evolve and verify a life-cycle balanced system can better deliver results that meet complex design objectives. This approach is systems engineering, but the framework presented is of limited generality. Hence the need for a more holistic approach to engineering design that would also include the life-cycle issues as well as 'digital service' functions, as illustrated in Figure 5.

Figure 5 A holistic view of engineering design (see online version for colours)

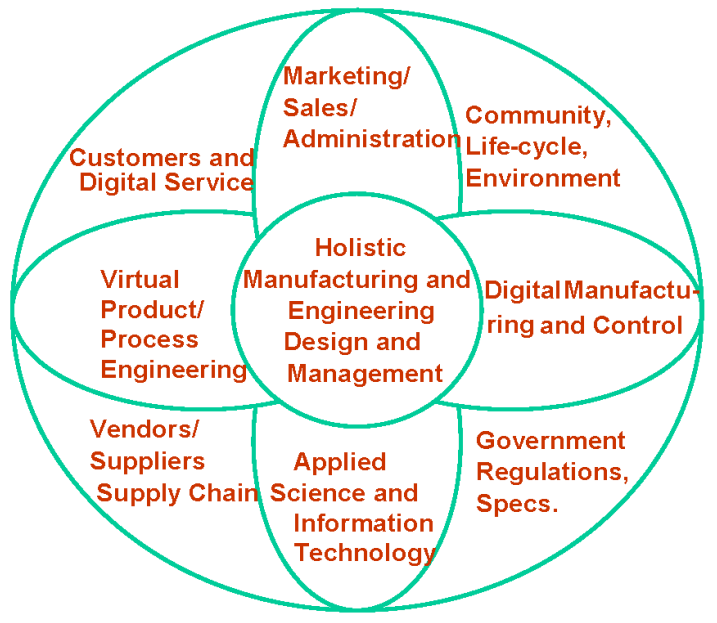




\section{Knowledge Management in collaborative engineering}

Modern systems analysis and design is about problem solving and computer applications. Ross and Schoman (1976) also emphasise the need to achieve a consensus among typically disparate parties: the user liaison personnel who interface with the developers, the 'professional' systems analyst, and management. Since all of these people have different interests and different viewpoints, it becomes all the more important that they have a common frame of reference - a common way of modelling the system-to-be. Well-structured methods and IT-tools are of key importance to support, not only to model the process, but also for effective management of information and its utilisation in the product design process. This potentially comprehensive approach can assist, for instance, in the more systematic analysis of the connection between the assembly sequence, detailed part design, jig and tool design, and quality control strategy; hence resulting in more robust engineering design. It is comprehensive in that it provides a framework for the consideration and comparison of design options, accounting for all phases in the life cycle of a product. It is consistent in that modern systems analysis and design methodologies and tools are utilised to innovate and design products, whether these products are artifacts or systems, including engineering systems and information systems. The approach is general and applies to both the logical or physical modelling levels.

Zachman (1987) has proposed a framework for information systems architecture which has seen wide spread attention. His matrix model framework is based on the concept that architecture means different things to different people. The rows correspond to 'perspectives' of different people or groups involved in the product realisation process, and the columns correspond to 'focuses' on different aspects. His framework suggests that information systems consist of three distinct 'product oriented' views: data, processes, and technology. Therefore it appears that this framework is general enough for various domains, including multi-disciplinary ones, and it is proposed here that it can be adapted to the information-based view of product design and manufacture. Some authors have used Zachman's framework for the structured systems analysis and design of computer information systems where they have substituted the name 'communications' for 'technology'.

It should be noted that John Zachman recognised the network dimension and included a technology-based communication column in his version of the framework, which today may be interpreted as internet/intranet communication between different engineering, business and/or manufacturing sites.

In this paper we present the part of this framework that can be used to represent the information-based design process model only. It is suggested to include the 'network' column which can represent the geographically distributed CE and distributed manufacturing focus, possibly using the world-wide-web technology- a subject of current interest. It should be noted, however, that the contextual row, in Zachman's complete framework, could represent the marketing perspective; the 'out-of-context' row can represent the components and subassembly suppliers' perspective and/or field service and retirement issues. However, these are considered, in the current context, to be beyond the scope of this paper. Therefore the proposed information-based view of product design and manufacture, in a rapid product realisation process and agile manufacturing is illustrated in Figure 6. 
Figure 6 A systems engineering architecture for a holistic design approach (see online version for colours)

\begin{tabular}{|c|c|c|c|c|c|c|}
\hline MODEL & $\begin{array}{l}\text { DATA } \\
\text { What? }\end{array}$ & $\begin{array}{c}\text { FUNCTION } \\
\text { How? }\end{array}$ & $\begin{array}{c}\text { NETWORK } \\
\text { Where? }\end{array}$ & $\begin{array}{l}\text { PEOPLE } \\
\text { Who? }\end{array}$ & $\begin{array}{l}\text { TIME } \\
\text { When? }\end{array}$ & $\begin{array}{c}\text { DRIVERS } \\
\text { why? }\end{array}$ \\
\hline $\begin{array}{l}\text { ENTERPRISE } \\
\text { MODEL } \\
\text { CONCEPTUAL }\end{array}$ & $\begin{array}{l}\text { Semantic } M \\
\text { Entities and } \\
\text { Relationships }\end{array}$ & $\begin{array}{l}\text { Business } \\
\text { Process Model } \\
\text { Feasibility Studies } \\
\text { DFx, Axiomatics }\end{array}$ & $\begin{array}{l}\text { Concurrent } \\
\text { Engineering } \\
\text { (CE) }\end{array}$ & $\begin{array}{l}\text { Organization } \\
\text { Units } \\
\text { Human resources, } \\
\text { education, training }\end{array}$ & Milestones, due & Business Plans \\
\hline $\begin{array}{l}\text { SYSTEM } \\
\text { MODEL } \\
\text { LOGICAL }\end{array}$ & $\begin{array}{l}\text { Embodiment, } \\
\text { Layout Design }\end{array}$ & Modules, integration & $\begin{array}{l}\text { Integrated Design \& } \\
\text { Distributed } \\
\text { manufacturing }\end{array}$ & $\begin{array}{l}\text { Human } \\
\text { Interface } \\
\text { Architecture }\end{array}$ & $\begin{array}{l}\text { Process Models } \\
\text { CAPP }\end{array}$ & 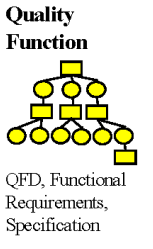 \\
\hline $\begin{array}{l}\text { TECHNOLOGY } \\
\text { MODEL } \\
\text { PHYSICAL }\end{array}$ & $\begin{array}{l}\text { Data Model } \\
\text { Detailed design, } \\
\text { CAD/CAMCAE }\end{array}$ & $\begin{array}{l}\text { System Design } \\
\text { Integrated design \& } \\
\text { Manufacturing, CIM }\end{array}$ & $\begin{array}{l}\text { Technology } \\
\text { Architecture }\end{array}$ & $\begin{array}{l}\text { Presentation } \\
\text { Architecture }\end{array}$ & 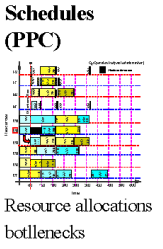 & $\begin{array}{l}\text { Design Rules } \\
\text { and Constraints } \\
\text { Quality assurance } \\
\text { Service conditions }\end{array}$ \\
\hline
\end{tabular}

\section{Conclusions}

In this paper, we introduced a KM framework and an underlying methodology and IT infrastructure to manage PD processes shared across several functions from inception to field service. The framework can be used for collaborative, distributed PD within the entire enterprise or across several enterprises. The framework is based on the Zachman framework, originally developed at IBM for Information Systems development. The proposed framework has four main layers: processes, models, tools, and physical layers.

This paper presents a systems analysis and design approach for engineering design process modelling. The approach proposes that all the design and methodology tools developed by many well recognised researchers, for particular contexts and phases of the design process, can be utilised within the proposed framework. The motivation is that even the latest CE approaches to design, as potent as they are, do not provide the complete framework to deal with complexities of current product realisation needs. The paper also reviewed significant contributions in engineering design, process design, systems analysis and design, as well as standards relating to the integration of various manufacturing activities. 


\section{References}

Bhatt, G.D. (2000) 'Organizing knowledge in the knowledge development cycle', Journal of Knowledge Management, Vol. 4, No. 1, pp.15-26.

Buchanan, B. and Smith, R. (1998) 'Fundamentals of expert systems', Annual Review of Computer Science, Vol. 3, No. 7, pp.23-58.

Dixon, J.R., and Poli, C. (1995) Engineering Design and Design for Manufacturing- A Structured Approach, Field Stone Publishers, Conway, Massachusetts, USA.

ElMaraghy, W.H. and Urbanic, R.J. (2003) 'Modelling of manufacturing systems complexity', Annals of CIRP, Vol. 52, No. 1, pp.363-366.

ElMaraghy, W.H. (2001) 'Systems analysis and design: an approach to information-based design process modeling', Keynote paper at the International CIRP Design Seminar, 6-8 June, Stockholm, Sweden, pp.41-46.

Loureiro, G. and Learny, P.G. (1999) 'A systems engineering framework for integrated automotive development', Proceedings of the 9th Annual International Symposium of the INCOSE, Vol. 1, pp.1173-1180.

Marshall, R., Leaney, P.G. and Botterell, P. (1998) 'Enhanced product realisation through modular design: an example of product/process integration', Proceedings of the SDPS/ASME/IEEE Third World Conference on Integrated Design and Process Technology, Berlin, Germany, ISSN 1090-9389, pp.143-150.

Pahl, G. and Beitz, W. (1976) Konstruktionslehre, Springer-Verlag, Berlin.

Ross, D.T. and Schoman, K.E. (1976) 'Structured analysis for requirements definitions', 2nd Int. Conf. Software Engineering, San Francisco, p.239.

Suh, N.P. (1988) 'Basic concepts in design for producibility', Annals of CIRP, Vol. 37, No. 2, pp.559-568.

Wagner, C. (2004) 'Breaking the knowledge acquisition bottleneck through conversational knowledge management', Information Resources Management Journal, Vol. 19, No. 1, 14 pages.

Zachman, J. (1987) 'A framework for information systems architecture', IBM Systems Journal, Vol. 26, No. 3, pp.276-292.

\section{Bibliography}

Harrington, J. (1984) Understanding the Manufacturing Process: Key to Successful CAD/CAM Implementation, Marcel Dekker, Inc., New York.

Mayer, R.J., Painter, M.K. and deWitte, P.S. (1992) IDEF Family of Methods for Concurrent Engineering and Business Re-engineering Applications, Knowledge-Based Systems, Inc., College Station, Texas, USA.

Merchant, M.E. (1997) 'The technological and social role of design in manufacturing - past, present and future', CIRP 1997 International Design Seminar Proceedings: Multimedia Technologies for Collaborative Design and Manufacturing, University of Southern California, USA, pp.xxi-xxvii.

Salminen, V., Yassine, A. and Riitahuhta, A. (2000) 'A strategic management framework for collaborative product development', 4th International Conference on Engineering Design and Automation, ED\&A, 30 July - 2 August, Orlando, Florida. 